Research Article

Tomasz P. Wiśniewski*

\title{
Should income be taken for granted as a sole driver of welfare? Bayesian insight on the relevance of non-income drivers of welfare
}

https://doi.org/10.2478/ijme-2018-0006

Received November 21, 2017; accepted March 16, 2018

Abstract: The paper consists of a discussion on the relevance of non-income drivers of welfare. This discussion is based on a subjective Bayesian reasoning, where welfare perceptions are subjectively rational decisions of individuals, who are, as author suggests, the ultimate decision-makers in respect of what welfare actually means for them.

The objective of the paper is to investigate if income should be taken for granted as a sole driver of welfare. The conclusion is drawn from a methodological investigation of this question in a Bayesian concept of probability with a consideration for correlations among income and non-income drivers of welfare. It suggests that income should not be taken for granted as a sole driver of welfare since the non-income factors, which are not correlated with income, appear to be relevantly affecting individuals' perceptions of welfare with Bayesian probability of almost $65 \%$.

Thereby, the paper is a reaffirmation of a need for further research in the area of welfare measures that might constitute an alternative to income-dominated indicators. Its value emanates from unambiguous answer in favour of the relevance of non-income drivers across welfare perceptions, which, without Bayesian reasoning, could remain unsolved at the point of 50\% odds for relevance (irrelevance).

Keywords: welfare, non-income welfare, subjectivism of welfare, drivers of welfare, welfare perception, welfare measurement, Bayesian probability

JEL codes: I 31, C 11

\section{Introduction}

Welfare is a complex philosophical concept that covers a socioeconomic well-being. Its complexity results from the fact that agents within the society may fare the welfare notion differently (Deardorff, 2014). A careful reading of welfare definition by Deardorff can attract readers' attention to the expression 'fare differently'. When we take this expression as a starting point for the discussion, we get a fundamental assumption for further reasoning in this paper - the assumption that welfare is a subjective concept that emanates different qualities for different people. Simplistically speaking, welfare is a concept that can be perceived differently throughout the society. Consequently, the paper is based on a subjective reasoning approach. This way of framing a concept of welfare makes the paper consistent with new classical economics, where according to Ikeda and Yagi (2012), the mainstream of economics belongs to the camp of subjectivism. The paper is equally anchored in neoclassical paradigm relating to rational expectations within the society. At this stage

*Corresponding author: Tomasz P. Wiśniewski, Collegium of World Economy, Warsaw School of Economics, Warsaw, Poland,

E-mail: tomasz.piotr.wisniewski@gmail.com

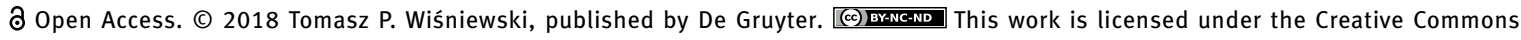
Attribution-NonCommercial-NoDerivs 4.0 License. 
(for simplicity), the discussion disregards evolutionary nature of welfare and does not cater to the fact that welfare perceptions may change dynamically over time.

The welfare perceptions can be driven by different factors. For the purposes of this paper, a segregation of welfare perception factors is based on a distinction between (i) income-related drivers of welfare perceptions (income drivers, income factors) and (ii) drivers that are not directly linked to income (nonincome drivers, non-income factors). The objective of this paper was to investigate if income should be taken for granted as a sole driver of welfare. The resulting investigation is supposed to answer a question whether non-income factors can relevantly affect welfare perceptions. Owing to a subjective nature of welfare perceptions, highlighted at the beginning, the subjectivism hidden in the above question is selfsame. I decided to employ Bayesian reasoning as a framework for this investigation, retaining the consistency of the paper with new classical economics. This allows using subjective probability interpretation for drawing the conclusions.

The remaining part of the paper is structured as follows. A brief literature review on the matters of (i) welfare subjectivism and individualism and (ii) welfare drivers not linked to income (Literature Review) is described next. This is then followed by an assessment of materiality of non-income factors through statistical reasoning under Bayesian concept of probabilities (Problem analysis under Bayesian reasoning). The paper ends with concluding remarks (Conclusions).

\section{Literature review}

\subsection{Subjectivism and individualism of welfare}

When reading the introduction of this paper, it may not be clear what is the meaning of the assumption made in respect of subjective nature of welfare perceptions. It may neither be clear what it triggers. A brief look at the history of economic thought however can be of a help to understand that matter. According to Ikeda and Yagi (2012), subjectivism started to play a role in economics in the late nineteenth century. This role emerged as a result of subjective way used in late classical economics to determine the prices, where the prices were determined through utility maximisation of individuals. This was evolutionary from an original objectivism canon of Smith who postulated that prices are determined by the cost of labour, capital and rent that are needed to produce goods (Smith, 2007) ${ }^{1}$. Then, such approach differences in determining prices between subjectivism and objectivism concepts can be translated into similar approach differences in perceiving welfare. As a result, we will have a subjectivism attitude on one hand, suggesting that welfare is determined through factors that are perceived individually by individuals, and an objectivism method of approaching welfare on the other hand, suggesting that it is determined through commonly known and accepted qualities - factor(s) that is given for everyone, no matter what are the individual attitudes towards such factor(s).

Furthermore, as already noted before, the assumption of subjectivism embedded in welfare perceptions is consistent with neoclassicism in economics, where the mainstream of economics is based on subjectivism. The increasing role of subjectivism in neoclassical economics started in 1930s when Hayek first discussed an inevitable role of subjectivism in economics and rejected the relevance of objectivism. He argued that most knowledge relating to economic behaviour is not a common knowledge but rather a private knowledge of agents involved in this behaviour (Hayek, 1937). However, regardless of the criticism about the role of objectivism in economic science, neoclassicism is still convinced (even if sceptically) that subjectivism and objectivism mutually coexist in economics. The result of such a conviction is that an objective outcome can be produced from economic analysis based on a subjective principle of utility maximisation (Ikeda and Yagi, 2012). Consequently, this might convince that investigating welfare as a subjective concept (likewise utility) is coherent with neoclassical canon.

1 The original edition of An Inquiry into the Nature and Causes of the Wealth of Nations by Adam Smith was first published in 1776. 
The view that welfare is subjective can also be derived from the analysis of Heathwood (2014) where he discussed opposite views of subjectivism versus objectivism used for conceptualisation of well-being. He based his analysis on the utilitarian theory and pointed out that conceptualisation of matters relating to well-being and welfare, or to quality of life, involves the same notion. All these topics are derived from a fundamental concept of well-being, which naturally becomes a philosophical question. He noted that, from Socratic perspective, subjectivism of well-being (and consequently welfare) means that something is good for individuals as a consequence of a favourable attitude towards this thing taken by these individuals. This suggests that a strong and common intuition may be a plausible reason for thinking about well-being as of matter of attitude or in other words, a subjective matter. Further reading of the analysis by Heathwood shows that subjectivism of welfare could also be derived from two popular theories of well-being: (i) hedonism, with its psychological hedonism postulate, and (ii) desire theory, also called as a preference satisfaction theory of welfare.

There is also a view represented by Lin (2017) that the subjectivism of welfare is actually a false feature. Lin argued that the falsity of welfare subjectivism can be drawn from potential divergence between the welfare of adults and the welfare of newborns. The argument suggests that welfare subjectivism, which implies that something has given quality for an individual (is good or bad), is the case if and only if, under the right conditions, this individual has appropriately given attitude towards it (favourable or not favourable). If so, such a theory of welfare should, according to Lin, be tested for what it implies about newborn infants. Consequent philosophical polemic is that such an argument could be rejected if actually tested for newborns, since neonatal welfare carries counterintuitive suggestions versus adults' welfare. This polemic however received a counterargument from Yelle (2016) who strived to avoid a criticism from Lin by distinguishing two types of welfare -welfare in qua human sense and welfare in qua person sense. He further claimed that a divergence observed in qua person, welfare on the example of adults and newborns, does not imply falsity of qua human welfare subjectivity.

In addition to the polemic about validity of welfare subjectivism, there are also works discussing a wider topic of welfare as a dynamic and individualism-driven concept. In this regard, Nelson and Winter (1982) claimed that evolutionary feature of economic reality calls for a need of evolutionary paradigm in welfare economics. These considerations are not directly defending the view of welfare subjectivism in favour of objectivism; however, they imply that its drivers should not be regarded as passive given variables. Such drivers evolve in time and are subject to individualism, what may indirectly suggest opting for subjectivism approach in researching welfare. The author believes that welfare linkage to individualism and subjectivism that is anchored in rational paradigm of neoclassicism may call for looking at welfare perceptions as at subjectively rational decisions made by the society. The concept of such decisions was defined by Gilboa (2009) and used in Gilboa et al. (2010). The subjectively rational decisions are, according to this work, decisions upon which a decision-maker cannot be convinced that they are wrong. The author further suggested to look at welfare perceptions through an angle of subjectively rational decisions. It may indeed not be feasible to convince an agent that his or her philosophical perception of welfare is wrong. Consequently, the author further claimed that such an angle brings into sharp focus the reliance of welfare perceptions on the beliefs of decision-makers. Then, if subjective beliefs are at stake, the reasoning in Bayesian world is somehow a natural direction to be taken in further part of the paper.

Even if concluding that welfare is a subjective matter resulting from its individualism-driven nature, the researchers tend to encounter another conceptual barrier. The question arises whether this individualism of welfare relates to utility or choice preferences of agents. Vanberg (2009) made a distinction between what he called a utility-individualism and a choice-individualism of welfare. Following his analysis:

Utility-individualism is interested in individual persons only as metering points from which utility values are collected, to be then processed in a social welfare calculus; the person as a sovereign chooser is lost out of sight [...] by contrast choiceindividualism looks at individuals as the ultimate sovereigns in social affairs whose voluntary and informed choices are the only source from which the observing economist can derive conclusions about social welfare (Vanberg, 2009, p. 4).

Advocating choice-individualism over utility-individualism might be a separate discussion; however, considerations for this topic are not in the scope of this paper. Nevertheless, the take-away for the herein 
paper from this distinct discussion is that welfare perceptions do originate from individual agents and are subject to their individualism and beliefs.

I also decided to refer to discussions about the nature of welfare in the debate by Keller (2009). His discussion may help to realize that any theory or paradigm regarding welfare can potentially earn criticism. Keller gave some logical reasoning for looking at welfare as a matter of individual subjective experiences. However, he subsequently suggested a counterargument for not treating welfare solely as a subjective experience and advocated some broader consideration. This counterargument is supported by the example of generating a fake experience for an individual to improve his or her experience himself or herself, without improving his or her actual welfare (or even worsening it). I suggest that looking at welfare as a matter of individual subjective perception, rather than individual subjective experience, could be a possibility for broadening welfare consideration. Indeed, individual's perception may equally be fake due to some manipulation but at least should not involve him or her in experiencing anything rationally harmful. Perception may appear less vulnerable than experience in terms of criticism around manipulations of mental state theory. Keller pointed out that similar counterargument can be addressed to desire theory of welfare. This is because individual's desire may not improve welfare at all (like a desire that stranger's medical treatment turns out successful - such a treatment outcome has no impact on individual's welfare). He further presented the cons of an informed desire theory applied to welfare to move towards objective list theory of welfare. Again, I claim that understanding welfare through an angle of perceptions instead of desires should neither involve desiring anything that could be selfdestroying nor involve targeting something not rationally important. So this might be potentially a way of conceptualising welfare so that its conceptualisation is less vulnerable to criticism. Nevertheless, the conclusion pertaining to all these theories and approaches is that each of them may be subject to criticism and counterarguments. This is due to complexity of welfare's nature, which is not easy to frame by one single and solely right theory.

\subsection{Non-income drivers of welfare}

I have observed that discussions, where a distinction between income and non-income dimensions of welfare is at stake, are often dominated by a topic of poverty. When it comes to discussions involving non-income welfare measurement, these debates tend to be dominated by poverty even more. My finding from literature review is that when jointly searching for terms 'welfare' and 'non-income' in abstracts of JSTOR database (across publications with abstracts), 50\% ${ }^{2}$ of publications included the word 'poverty'. Furthermore, when jointly searching for terms 'welfare' and 'non-income' in abstracts of JSTOR database (across publications with abstracts and comprising word 'measure'), more than $56 \%{ }^{3}$ of publications included the word 'poverty'. The corresponding results for ScienceDirect database suggested weaker (but still) dominance of poverty considerations with results of $43 \%$ and $45 \%$, respectively ${ }^{4}$, whereas a ProQuest database sample showed an extensive domination of poverty issues with more than $57 \%$ and $85 \%$ results, respectively ${ }^{5}$. This phenomenon of - one could say - overpresence of poverty in non-income welfare considerations - which I want to rebalance - is equally apparent in the case of discussion by Zhuang (2011). Nonetheless, I refer to Zhuang's work since (in my opinion) it draws a relevant conclusion in light of herein discussion that 'the relationship between income and non-income welfare attainment cannot be taken for granted'. Following Zhuang further, the improvements in non-income welfare do contribute to economic growth, i.e. contribute to income dimension of welfare; however, improvements in economic growth may not necessarily improve non-income dimension of welfare. Given a common sense, the arguments of Zhuang may seem accurate, as in general, the data and past experience can provide evidence for contradiction between income growth and inertia (or deterioration) of non-income qualities in a society. Consistently with such evidence, Skidelsky,

2 Result of 101 instances out of 202 records in JSTOR.

3 Result of 66 instances out of 117 records in JSTOR.

4 Result of 136 instances out of 319 records and 126 instances out of 282 records in Science Direct, respectively.

5 Result of 12 instances out of 21 records and 12 instances out of 14 records in ProQuest, respectively. 
emeritus professor of political economy at the University of Warwick, claimed in 2012 that 'it is increasingly understood that economic growth does not necessarily increase our sense of well-being'.

Various measures of welfare considering the non-income components of welfare or non-income wellbeing can be found in the literature. A concept of net economic welfare, introduced by Nordhaus and Tobin, is one of the discussions where non-income considerations of welfare are allowed (Nordhaus and Tobin, 1972). As a result of a question whether past economic growth had been a growth in any meaningful sense, Nordhaus and Tobin started looking at welfare from a wider perspective. They allowed for some of known discrepancies between gross national product and a general notion of economic welfare by constructing (how they called it) a primitive and experimental measure. The measure of net economic welfare tried to capture social cost of factors such as pollution or crime (i.e. to somehow capture non-income considerations) when measuring national income. They were sceptical themselves about the controversy of their concept and measure, as well as aware of corresponding limitations in terms of calculus. However, they justified introduction of their concept, despite expected criticism, by the virtue of producing relevant welfareoriented measure, which was at that moment a compelling challenge to economists.

I uncovered two phenomena in the existing literature: (i) non-income drivers of welfare tend to be mainly discussed alongside poverty issues, so within a pejorative side of welfare rather than across entirety of welfare scope and (ii) non-income drivers of welfare are often discussed jointly with incomerelated measures and are more rarely analysed in isolation from income. The following section will be a brief review of literature where non-income drivers of welfare are discussed and analysed under criteria of isolation from income measures and in respect of the entire scope of welfare, i.e. in both poverty and wellbeing senses. Among the apparent non-income drivers of welfare that have received attention in research (given both criteria flagged above), I decided to signal two of them: employment well-being and climate and environmental conditions. Another area of review and discussion could be evidence for - intuitively obvious - impact of health, including mental health, on welfare. This area however will not be covered in the following very concise literature review. When it comes to employment well-being, the work of Helliwell and Huang (2010) reveals significance of influence of non-financial job characteristics on life satisfaction and workplace efficiency by deriving findings from three Canadian surveys conducted in 2002 and 2003. At the beginning, Helliwell and Huang referred to Adam Smith's feature of the job, called the agreeableness or disagreeableness. They further referred to a quality of workplace trust as a measure of social capital and claimed that the research had largely ignored social capital and life satisfaction in the workplace before. They then pointed out that there have been other papers exploring the linkages between job satisfaction and job performance, exemplifying the work of Judge et al. (2001). Another instance of employment well-being linkage to life satisfaction is demonstrated by Kassenboehm and Haisken-DeNew (2009). They articulated that economists had been keenly interested in determining the effect of labour market status on life satisfaction, especially unemployment implications. Their work examined the impact of unemployment on life satisfaction for men and women in Germany during the period between 1991 and 2006 and concluded that the negative and significant psychological effects of unemployment generally remain fairly constant over the whole period and similar in magnitude. Additionally, certain evidence for even increased vulnerability of women to such effects was equally discussed. I suggest that given a significant size of German population, the findings of Kassenboehm and Haisken-DeNew are worth noting. When it comes to climate and environmental conditions, the research of Dietz et al. (2016) published by Princeton University is an example of recent debate regarding impact of climate changes on future generations' welfare. They discussed that valuation of future generations' welfare is somewhat an ethical matter dependent on societal preferences. Their work referred to a larger notion of welfare that recognizes that changes in dollar terms alone may not be the best way to measure the degree to which a particular person is better off. They argued how to approach an intergenerational trade-off between cost and benefit of climate changes' impact on social welfare. Dietz et al. not only claimed that climate and related changes do influence social welfare but also strived to convince that welfare of future generations may simply be threatened if current economic analyses and decision-making disregard intergenerational implications of climate changes. I read it as an implicit evidence by Dietz et al. (2016) that welfare in a larger sense, i.e. societal welfare across income and non-income dimensions, does depend on climate variables. 
Furthermore, Frijters and Van Praag (1998) made such a suggestion explicit by advocating that 'it is well known that differences in climate affect the quality of life'. Their analysis of data from a large survey in Russia concluded that well-being in Russia is influenced negatively by harsh winters but benefits from the number of sun hours. Going further, the stickiness factor and high levels of humidity together with high temperatures were seen to have a strong negative influence on well-being. One still can argue against such a view but indeed climate appears to matter for welfare.

\section{Problem analysis under Bayesian reasoning}

\subsection{The problem}

Should income be taken for granted as a sole driver of welfare? This question raised in the paper's title is difficult to answer. The difficulty is as a result of a vague problem to which the question strives to refer - the problem of how welfare is perceived by people and how it can be measured. Such a question is especially hard to answer in an ordinary concept of probability based on frequencies. After having reviewed the literature in the previous section, I have provided some evidence for subjectivity of welfare and suggested to look at welfare as a matter of individual subjective perception. Hence, the answer to our question is dependent on the outcome of perception by individual agents.

If anchored in an ordinary concept of probability, it will be like a coin toss where there are two possible outcomes. In this case, if a coin is unbiased, both of these results are equally likely (Hogben, 1993). Such evenly distributed probabilities of outcomes are observed when the number of observations (coin tosses) increases. The same applies to perception of welfare by individuals, in which case, if society is unbiased, some people will perceive the given factor as representing something 'good for them' and some others will neglect such a given factor when assessing their welfare, treating it as an irrelevant one. Consequently, when expanding the sample size of individuals, so that it represents the whole society, the perception may become evenly divided, and the answer to the question will be that half of the society will claim that income can be a sole driver of welfare and the other half will claim the opposite. Coming back to probability, its concept based on frequencies may be good for a coin toss problem, as pointed by DeDeo (2016), since one can toss a coin multiple times to check what happens and use these observations to attribute an objective probability. However, for the question I raised, such objective probability derived from observations could turn out meaningless, as the question is referring to an ambiguous and subjective matter. Objective probability would very much assume that there is one predefined objective answer that can be derived from observations, which we know is not the case for welfare. If the number of such observations is big enough to make the law of large numbers work, answering the main question of the paper could conclude with expected half-half outcome: half of the society think that income can be a sole driver of welfare and it can be taken for granted, and the other half think that it cannot be a sole driver of welfare and should not be taken for granted, full stop. However, the problem remains unsolved if less than the whole society is considered and the problem is researched on the level of individuals.

\subsection{Conversion of the problem towards Bayesian concept of probability}

The research question of whether income should be taken for granted as a sole driver of welfare might however be turned into a methodological problem to solve. This can be achieved by moving it towards Bayesian concept of probability. Such a concept is based on subjective states of beliefs rather than frequency. The use of Bayes' theorem has a power of inverting some difficult questions that are hard to answer into questions that can be answered more easily, even if they seem bizarre (DeDeo, 2016). DeDeo explained that the reasoning beyond Bayes' theorem requires a segmentation of variables into a set of exhaustive theories about the world (T) and the data that may populate these theories (D). Consequently, the analysis of our problem will be based on such segmentation (Table 1). This segmentation illustrates four combinations relating to problem's theories of the world (T) and problem's data that populate such theories (D) for non- 
income factors of welfare. The non-income factors, defined in the introduction of the paper, are summarised in the following (Table 2). Ultimately, the analysis will be based on the following architecture:

$T=\left\{t_{1}=\right.$ the non-income factors affect perception of welfare, 'affect';

$t_{2}=$ the non-income factors do not affect perception of welfare, 'not affect'

$\mathrm{D}=\left\{\mathrm{d}_{1}=\right.$ the non-income factors are correlated with income, 'correlated';

$\mathrm{d}_{2}=$ the non-income factors are not correlated with income, 'not correlated' $\}$

Table 1. Segmentation of variables used for problem analysis

\begin{tabular}{cll}
\hline & \multicolumn{2}{c}{ Correlation of non-income factors with income } \\
\cline { 2 - 3 } $\begin{array}{c}\text { Impact on } \\
\text { perception of } \mathrm{d}_{1} \text { : the non-income factors affect perception } \\
\text { welfare }\end{array}$ & $\begin{array}{l}\mathrm{t}_{1}, \mathrm{~d}_{2} \text { : the non-income factors affect perception of } \\
\text { of welfare, and given factors are correlated with } \\
\text { income }\end{array}$ \\
$\begin{array}{ll}\text { income } \\
\mathrm{t}_{2}, \mathrm{~d}_{1} \text { : the non-income factors do not affect } \\
\text { perception of welfare, and given factors are }\end{array}$ & $\begin{array}{l}\mathrm{t}_{2}, \mathrm{~d}_{2} \text { : the non-income factors do not affect } \\
\text { perception of welfare, and given factors are not } \\
\text { correlated with income }\end{array}$ \\
& correlated with income &
\end{tabular}

Source: Own elaboration.

Table 2. Segregation of welfare perception factors

\begin{tabular}{cll}
\hline \multirow{2}{*}{$\begin{array}{c}\text { Correlation of } \\
\text { factors with } \\
\text { income }\end{array}$} & $\begin{array}{l}\text { Income dimension } \\
\text { of welfare }\end{array}$ & $\begin{array}{l}\text { Income factors or income drivers of welfare } \\
\text { Non-income factors }\left(\mathrm{d}_{1}\right) \text { or non-income drivers of welfare, which have statistically } \\
\text { significant correlation with income }\end{array}$ \\
\cline { 2 - 3 } & $\begin{array}{l}\text { Non-income dimension } \\
\text { of welfare }\end{array}$ & $\begin{array}{l}\text { Non-income factors }\left(\mathrm{d}_{2}\right) \text { or non-income drivers of welfare, which do not have } \\
\text { statistically significant correlation with income }\end{array}$ \\
\hline
\end{tabular}

Source: Own elaboration.

Lemma 1: When the correlation of non-income factor(s) with income is significant, then the non-income factor $\left(d_{1}\right)$ is dependent on income. Consequently, this dependence implies that income measurements implicitly include welfare, which would be measured by correlated non-income factor $\left(\mathrm{d}_{1}\right)$, and nonincome factor $\left(\mathrm{d}_{1}\right)$ remains in the income dimension of welfare. Such an implication has a form of rational expectations across the society.

$$
\mathbf{P}\left(\mathbf{t}_{1} \mid \mathbf{d}_{1}\right)=\mathbf{0} \text { and } \mathbf{P}\left(\mathbf{t}_{2} \mid \mathbf{d}_{1}\right)=\mathbf{1}
$$

Lemma 2: When the correlation of non-income factor(s) with income is insignificant or there is no such correlation, then the non-income factor $\left(\mathrm{d}_{2}\right)$ is independent of income. Consequently, this independence implies that income measurements (income factors) do not include welfare measured by uncorrelated nonincome factor $\left(\mathrm{d}_{2}\right)$, and such an implication has a form of rational expectations across the society.

$$
\mathbf{P}\left(\mathbf{t}_{1} \mid \mathbf{d}_{2}\right)>\mathbf{0} \text { and } \mathbf{P}\left(\mathbf{t}_{2} \mid \mathbf{d}_{2}\right)<1
$$

Now, since the reasoning moved to subjective Bayesian concept, the probability of variables will depend on how people believe they are rather than on what they are, i.e. the variables describe perceptions. I assume even distribution (half-half) of such beliefs regarding two theories about the world in our problem $\left(\mathrm{t}_{1}\right.$ and $t_{2}$ ) - assumption that the probability distribution between them ('affect' vs. 'not affect') is even:

$\mathrm{P}\left(\mathrm{t}_{1}\right)=0.5$ (probability that the non-income factors affect perception of welfare is $50 \%$ ).

$\mathrm{P}\left(\mathrm{t}_{2}\right)=1-0.5=0.5$ (probability that the non-income factors do not affect perception of welfare is $50 \%$, as probabilities of state $t_{1}$ and state $t_{2}$ are exhaustive). 
The assumption of a 50\%:50\% probability is a common sense arbitrary assumption. This is because a 50\%:50\% neutral probability is assumed to be a likely outcome under an empirical assessment of $\mathrm{P}\left(\mathrm{t}_{1}\right)$ or $\mathrm{P}\left(\mathrm{t}_{2}\right)$, providing a large sample of individuals ${ }^{6}$. It is important to notice that by stating that factors are correlated with income, I refer to statistically significant correlation relationship for these variables. Accordingly, when factors are being called as not correlated, they should not only be read as variables with zero correlation but equally variables with no statistically significant correlation (insignificant correlation).

The process of answering the question of whether income should be taken for granted as a sole driver of welfare will now follow a sequence assessment of selected Bayesian probabilities to ultimately draw the conclusion. The conclusion will be based on the probability measure of $\mathrm{P}\left(\mathrm{t}_{1} \mid \mathrm{d}_{2}\right)$ :

$\mathrm{P}\left(\mathrm{t}_{1} \mid \mathrm{d}_{2}\right)=$ the probability that the non-income factors affect perception of welfare if such factors are not correlated with income.

$$
\begin{aligned}
& \mathrm{P}\left(\mathrm{t}_{1} \mid \mathrm{d}_{2}\right)=\frac{\mathrm{P}\left(\mathrm{d}_{2} \mid \mathrm{t}_{1}\right) \cdot \mathrm{P}\left(\mathrm{t}_{1}\right)}{\mathrm{P}\left(\mathrm{d}_{2}\right)} \\
& \mathrm{P}\left(\mathrm{d}_{2}\right)=\mathrm{P}\left(\mathrm{d}_{2} \mid \mathrm{t}_{1}\right) \cdot \mathrm{P}\left(\mathrm{t}_{1}\right)+\mathrm{P}\left(\mathrm{d}_{2} \mid \mathrm{t}_{2}\right) \cdot \mathrm{P}\left(\mathrm{t}_{2}\right) \\
& \mathrm{P}\left(\mathrm{t}_{1} \mid \mathrm{d}_{2}\right)=\frac{\mathrm{P}\left(\mathrm{d}_{2} \mid \mathrm{t}_{1}\right) \cdot \mathrm{P}\left(\mathrm{t}_{1}\right)}{\mathrm{P}\left(\mathrm{d}_{2} \mid \mathrm{t}_{1}\right) \cdot \mathrm{P}\left(\mathrm{t}_{1}\right)+\mathrm{P}\left(\mathrm{d}_{2} \mid \mathrm{t}_{2}\right) \cdot \mathrm{P}\left(\mathrm{t}_{2}\right)} \\
& \mathrm{P}\left(\mathrm{t}_{1} \mid \mathrm{d}_{2}\right)=\frac{1}{1+\mathrm{A}}, \mathrm{A}=\frac{\mathrm{P}\left(\mathrm{d}_{2} \mid \mathrm{t}_{2}\right) \cdot \mathrm{P}\left(\mathrm{t}_{2}\right)}{\mathrm{P}\left(\mathrm{d}_{2} \mid \mathrm{t}_{1}\right) \cdot \mathrm{P}\left(\mathrm{t}_{1}\right)}
\end{aligned}
$$

$\mathrm{P}\left(\mathrm{d}_{2} \mid \mathrm{t}_{1}\right)=$ the probability that non-income factors are not correlated with income if the non-income factors affect perception of welfare.

$\mathrm{P}\left(\mathrm{d}_{2} \mid \mathrm{t}_{2}\right)=$ the probability that non-income factors are not correlated with income if the non-income factors do not affect perception of welfare.

Now, turning the problem into Bayesian concept of probability will enable overcoming the issue of answering a question that is hard to answer:

$\mathrm{P}\left(\mathrm{t}_{1} \mid \mathrm{d}_{2}\right)$ - what is the probability that the non-income factors affect perception of welfare if such factors are not correlated with income?

by swapping it to questions that can be answered based on the intuition:

$\mathrm{P}\left(\mathrm{d}_{2} \mid \mathrm{t}_{1}\right)$ - what is the probability that the non-income factors are not correlated with income if such factors affect perception of welfare?

and

$\mathrm{P}\left(\mathrm{d}_{2} \mid \mathrm{t}_{2}\right)$ - what is the probability that the non-income factors are not correlated with income if such factors do not affect perception of welfare?

The $\mathrm{P}\left(\mathrm{t}_{1} \mid \mathrm{d}_{2}\right)$ question is difficult to answer as it depends on beliefs of people (their perception). However, the swapping questions $\mathrm{P}\left(\mathrm{d}_{2} \mid \mathrm{t}_{1}\right)$ and $\mathrm{P}\left(\mathrm{d}_{2} \mid \mathrm{t}_{2}\right)$ are easier to answer since they can be based on logical thinking (or logical intuition) rather than on subjective assessment of individual beliefs.

6 It would be like an empirical coin toss, where there are two possible outcomes, and (if the number of observations is big enough to make the law of large numbers work) both of these outcomes are equally likely. 


\subsection{The analysis of the problem}

I will now assess the magnitude of probability $\mathrm{P}\left(\mathrm{d}_{2} \mid \mathrm{t}_{1}\right)$, i.e. the probability that the non-income factors are not correlated with income, providing that such factors affect perception of welfare. The assessment will be performed assuming the $50 \%$ odds relating to a common conviction of people for a probability that the non-income factors affect perception of welfare. In other words, I will strive to assess what is a chance to get the data, which will imply that non-income factor(s) is not correlated with income, given that such nonincome factor(s) affects perceptions of welfare, all under the assumption that half of people is convinced that non-income factors affect perception of welfare and the other half is convinced on the opposite. Based on logical intuition, it is highly likely that if non-income factor(s) affects perception of welfare, there is a chance of getting data that will demonstrate that such factor(s) is not correlated with income measurements. Apparently, this is especially valid for individuals with income above a certain level. The empirical data of the Gallup organisation suggest that above a certain level of stable income, individuals' emotional wellbeing is determined by factors other than income, referred to as 'other factors in temperament of people and circumstances of life' (Kahneman and Deaton, 2010). Such factors may imaginably indeed be uncorrelated with income. This is also because when non-income factor(s) affects perception of welfare, then this particular factor is somehow an effective measure of welfare. If so, it is then likely that this measure is independent of income. Moreover, I illustrate the above intuition-based reasoning by an example of climate. Intuitively, and based on the exemplary evidence in the work of Frijters and Van Praag (1998), a bad climate affects (impairs) welfare of people living around, and conversely, a good climate affects (enhances) welfare of people. This all has an influence on these people (societies), regardless of their income (national income). Reasonably, the magnitude of probability of $\mathrm{P}\left(\mathrm{d}_{2} \mid \mathrm{t}_{1}\right)$ should be high - more than $50 \%$ of common conviction probability, however not extreme. I assess it at $90 \%$. Read it as: 'if non-income factor(s) affects perception of welfare, then the belief probability that this non-income factor(s) is not correlated with income is $90 \%$ '. I do not set this degree of belief at $100 \%$, to allow for some unobvious associations between income and welfare-affecting non-income drivers, especially due to a large theoretical variety of non-income factors.

Similarly, I will now assess the magnitude of probability of $\mathrm{P}\left(\mathrm{d}_{2} \mid \mathrm{t}_{2}\right)$, i.e. the probability that non-income factors are not correlated with income, providing that such factors do not affect perception of welfare. Again, the assessment will be performed assuming the $50 \%$ odds relating to a common conviction of people for (this time) a probability that the non-income factors do not affect perception of welfare. The assessment looks at what is a chance of getting a datum that will imply that non-income factor(s) is not correlated with income, given that such non-income factor(s) does not affect perceptions of welfare, all under the assumption that half of people is convinced that non-income factors affect perception of welfare and the other half is convinced on the opposite. Intuitively, when non-income factor(s) does not affect perception of welfare, a chance of getting these data is relatively small. This is due to the logic that if a non-income factor does not affect perception of welfare, it is not an effective measure of welfare and people do not care about it (when talking about welfare). They may not care about this non-income factor for two reasons. The first reason is that the socioeconomic quality measured by a given factor is dependent on income (correlated with income) and already implicitly measured by income. This reason is however not applicable here, as in this instance, we consider a factor that is not correlated with income $\left(\mathrm{d}_{2}\right)$. The second reason is that people do not care about non-income factors since they represent qualities of no relevance for them when considering their welfare. Imaginably, these factors can either have correlation with income or not. Read it as: 'if non-income factors do not affect perception of welfare, then the belief probability that those nonincome factors are not correlated with income is 50\%'. I set this degree of belief at 50\% for simplicity. Moreover, assigning empirical weights to either side could end up with no other result whatsoever, given possibly infinite quantity of irrelevant factors (law of large numbers).

The abovementioned logic-driven assessments allowed for setting the probabilities of $\mathrm{P}\left(\mathrm{d}_{2} \mid \mathrm{t}_{1}\right)$ and $\mathrm{P}\left(\mathrm{d}_{2} \mid \mathrm{t}_{2}\right)$. This is now a basis for assessing the probability of the question $\mathrm{P}\left(\mathrm{t}_{1} \mid \mathrm{d}_{2}\right)$, which previously used to be the question difficult to answer due to its reliance on beliefs of people. The Bayesian equation (3) for our problem is now the following: 
$\mathrm{P}\left(\mathrm{t}_{1} \mid \mathrm{d}_{2}\right)=\frac{\mathrm{P}\left(\mathrm{d}_{2} \mid \mathrm{t}_{1}\right) \cdot \mathrm{P}\left(\mathrm{t}_{1}\right)}{\mathrm{P}\left(\mathrm{d}_{2} \mid \mathrm{t}_{1}\right) \cdot \mathrm{P}\left(\mathrm{t}_{1}\right)+\mathrm{P}\left(\mathrm{d}_{2} \mid \mathrm{t}_{2}\right) \cdot \mathrm{P}\left(\mathrm{t}_{2}\right)}=\frac{90 \% \cdot 50 \%}{90 \% \cdot 50 \%+50 \% \cdot 50 \%}=\frac{45 \%}{45 \%+25 \%}=\frac{45 \%}{70 \%}=\mathbf{6 4 . 2 9 \%}$

The interpretation of this equation result will be that it is more likely (almost $65 \%$ probability) that the non-income factors affect perception of welfare, given that these factors are not correlated with income, compared to $50 \%$ probability for assumed common conviction of people that the non-income factors affect perception of welfare. Consequently, the answer to the research question of the paper:

Should income be taken for granted as a sole driver of welfare?

is

No, the income should not be taken for granted as a sole driver of welfare, since the non-income factors not correlated with income have a Bayesian probability of almost $65 \%$ to be relevantly affecting welfare perceptions, which is higher than assumed neutral $50 \%$ probability for a common conviction of people that the non-income factors affect perception of welfare.

In other words, it is not only a matter of intuition but equally a matter of fact based on high Bayesian subjective probability that there are factors other than income, and not related to income, that count for people when perceiving welfare.

\section{Conclusions}

Throughout the paper, I tried to defend a view that subjectivism approach to welfare concept is indispensable for investigating its inherent drivers in a methodological manner. The literature review contained in the commencing section might convince that investigating welfare as a subjective concept, likewise a concept of utility, is coherent with neoclassical canon. I further suggest to look at welfare perceptions through an angle of subjectively rational decisions, since such an angle brings into a sharp focus the reliance of welfare perceptions on the beliefs of individuals. These individuals are, as I suggest, the ultimate decisionmakers in respect of what welfare actually means for them. This view is consistent with a concept of choiceindividualism of welfare by Vanberg (2009).

The welfare perceptions can be driven by different factors, which for the purposes of methodological investigation were segregated into income and non-income factors (or drivers) spread throughout income and non-income dimensions of welfare. Furthermore, the methodological investigation on paper's research question of whether income should be taken for granted as a sole driver of welfare was set up in a Bayesian concept of probability. After having considered possible correlation associations among welfare drivers, after having swapped this research question into questions that can be answered based on logical reasoning and after using Bayes' theorem, I was able to conclude. The conclusion was that the income should not be taken for granted as a sole driver of welfare, since the non-income factors that are not correlated with income have a high ${ }^{7}$ Bayesian probability of almost $65 \%$ for affecting welfare perceptions.

I believe that this paper offers certain academic contribution to welfare economics. First, the implication is that it reaffirms a need for prospective further research on alternative welfare measurements. Second, it articulates that consideration for correlations to existing metrics, like correlations to GDP measure of income, is indispensable when investigating the alternate welfare metrics. Therefore, the paper suggests that research on alternative welfare measurements should rather focus on gaps that are not implicitly measured by income metrics. Subsequently, practical implications take a form of potential alternative measures that extend current quantifications of welfare in a value-adding scope. The expected result is that the

7 Respective to the assumed 50\% probability for people's conviction that the non-income factors affect their welfare perceptions. 
paper initiates a work on metrics (tools) that add marginal coverage to current income-dominated welfare measurements and does limit a work on extensions that risk a double counting of income-related variables. Consequently, the paper is fostering an alignment between the perception of welfare by individuals and the 'creation' of welfare by policy-makers. This could be ultimately contributing to a better policy-making in general.

\section{References}

Deardorff, A.V. (2014), “Welfare”, Deardorffs’ Glossary of International Economics, retrieved from University of Michigan resources [1 September 2017].

DeDeo, S. (2016), Bayesian Reasoning for Intelligent People, Draft paper of the Carnegie Mellon University and the Santa Fe Institute.

Dietz, S., Groom, B., Pizer, W.A. (2016), Weighing the costs and benefits of climate change to our children, The Future of Children, Vol. 26, No. 1, pp. 133-155.

Frijters, P., Van Praag, B.M.S. (1998), The effects of climate on welfare and wellbeing in Russia, Climate Change, Vol. 39, pp. 61-81.

Gilboa, I. (2009), Theory of decision under uncertainty, Econometric Society Monograph Series, Vol. 45, Cambridge University Press, New York.

Gilboa, I., Maccheroni, F., Marinacci, M., Schmeidler, D. (2010), Objective and subjective rationality in a multiple prior model, Econometrica, Vol. 78, pp. 755-770.

Hayek, F.A. (1937), Economics and knowledge, Economica, Vol. 4, No. 13, pp. 33-54.

Heathwood, C. (2014), Subjective theories of well-being, in: B. Eggleston, D.E. Miller, (Eds), The Cambridge companion to utilitarianism, Cambridge University Press, Cambridge, pp. 199-219.

Helliwell, J.F., Huang, H. (2010), How's the job? Well-being and social capital in the workplace, Industrial and Labor Relations Review, Vol. 63, No. 2, pp. 205-227.

Hogben, L. (1993), Mathematics for the million: how to master the magic of numbers, W.W. Norton \& Company, London.

Ikeda, Y., Yagi, K. (2012), Subjectivism and objectivism in the history of economic thought, Routledge, London.

Judge, T.A., Thoresen, C.J., Bono, J.E., Patton, G.K. (2001), The job satisfaction - job performance relationship: a qualitative and quantitative review, Psychological Bulletin, Vol. 127, No. 3, pp. 376-407.

Kahneman, D., Deaton, A. (2010), High income improves evaluation of life but not emotional well-being. Proceedings of the National Academy of Sciences of the United States of America, Vol. 107, No. 38, pp. 16489-16493.

Kassenboehm, S.C., Haisken-DeNew, J.P. (2009), You're Fired! The causal negative effect of entry unemployment on life satisfaction, The Economic Journal, Vol. 119, No. 536, pp. 448-462.

Keller, S. (2009), Welfare as success, Noûs, Vol. 43, No. 4, pp. 656-683.

Lin, E. (2017), Against welfare subjectivism, Noûs, Vol. 51, No. 2, pp. 354-377.

Nelson, R.R., Winter, S.G. (1982), An evolutionary theory of economic change, The Belknap Press of Harvard University Press, Cambridge and London.

Nordhaus, W.D., Tobin, J. (1972), Is growth obsolete?, Economic Research: Retrospect and Prospect, Vol. 5, pp. 1-80.

Skidelsky, R. (2012), Happiness, equality and the search for economic growth, The Guardian, retrieved from The Guardian international edition [30 September 2017].

Smith, A. (2007), An inquiry into the nature and causes of the wealth of nations, MetaLibri Digital Library, Lausanne.

Vanberg, V. (2009), Evolving preferences and policy advice in democratic society, The papers on economics and evolution \#0919, Max Planck Institute of Economics, Jena.

Yelle, B. (2016), In defense of sophisticated theories of welfare, Philosophia, Vol. 44, No. 4, pp. 1409-1418.

Zhuang, J. (2011), Poverty, inequality, and inclusive growth in Asia: measurement, policy issues, and country studies, Anthem Press, London. 